\title{
High-resolution $\mathrm{NO}_{2}$ remote sensing from the Airborne Prism EXperiment (APEX) imaging spectrometer
}

\author{
C. Popp ${ }^{1}$, D. Brunner ${ }^{1}$, A. Damm ${ }^{2}$, M. Van Roozendael ${ }^{3}$, C. Fayt ${ }^{3}$, and B. Buchmann ${ }^{1}$ \\ ${ }^{1}$ Empa, Swiss Federal Laboratories for Materials Science and Technology, 8600 Dübendorf, Switzerland \\ ${ }^{2}$ Remote Sensing Laboratories, University of Zurich, Winterthurerstrasse 190, 8057 Zurich, Switzerland \\ ${ }^{3}$ Belgian Institute for Space Aeronomy (BIRA-IASB), Avenue Circulaire 3, 1180 Brussels, Belgium
}

Correspondence to: D. Brunner (dominik.brunner@empa.ch)

Received: 1 March 2012 - Published in Atmos. Meas. Tech. Discuss.: 28 March 2012

Revised: 1 August 2012 - Accepted: 21 August 2012 - Published: 13 September 2012

\begin{abstract}
We present and evaluate the retrieval of high spatial resolution maps of $\mathrm{NO}_{2}$ vertical column densities (VCD) from the Airborne Prism EXperiment (APEX) imaging spectrometer. APEX is a novel instrument providing airborne measurements of unique spectral and spatial resolution and coverage as well as high signal stability. In this study, we use spectrometer data acquired over Zurich, Switzerland, in the morning and late afternoon during a flight campaign on a cloud-free summer day in June 2010. $\mathrm{NO}_{2}$ VCD are derived with a two-step approach usually applied to satellite $\mathrm{NO}_{2}$ retrievals, i.e. a DOAS analysis followed by air mass factor calculations based on radiative transfer computations. Our analysis demonstrates that APEX is clearly sensitive to $\mathrm{NO}_{2} \mathrm{VCD}$ above typical European tropospheric background abundances $\left(>1 \times 10^{15}\right.$ molec $\left.\mathrm{cm}^{-2}\right)$. The two-dimensional maps of $\mathrm{NO}_{2} \mathrm{VCD}$ reveal a very convincing spatial distribution with strong gradients around major $\mathrm{NO}_{\mathrm{x}}$ sources (e.g. Zurich airport, waste incinerator, motorways) and low $\mathrm{NO}_{2}$ in remote areas. The morning overflights resulted in generally higher $\mathrm{NO}_{2} \mathrm{VCD}$ and a more distinct pattern than the afternoon overflights which can be attributed to the meteorological conditions prevailing during that day with stronger winds and hence larger dilution in the afternoon. The remotely sensed $\mathrm{NO}_{2} \mathrm{VCD}$ are also in reasonably good agreement with ground-based in-situ measurements from air quality networks considering the limitations of comparing column integrals with point measurements. Airborne $\mathrm{NO}_{2}$ remote sensing using APEX will be valuable to detect $\mathrm{NO}_{2}$ emission sources, to provide input for $\mathrm{NO}_{2}$ emission modelling, and to establish links between in-situ measurements, air quality models, and satellite $\mathrm{NO}_{2}$ products.
\end{abstract}

\section{Introduction}

Nitrogen dioxide $\left(\mathrm{NO}_{2}\right)$ is an important reactive trace gas in the troposphere. $\mathrm{NO}_{2}$ acts as an ozone and aerosol precursor and can directly or indirectly affect human health (e.g. pulmonary or cardiovascular diseases) (Brunekreef and Holgate, 2002) and ecosystem functions and services (e.g. damage of leaves, reduction of crop production, acidification) (Bell and Treshow, 2002). Besides natural sources such as lightning and soil emissions, the major fraction of tropospheric $\mathrm{NO}_{2}$ is related to anthropogenic activities, notably fossil fuel combustion by traffic and industry. Despite significant improvements of air quality in European countries during the past two decades, air quality thresholds are still frequently exceeded and further efforts are needed particularly regarding reductions of particulate matter, ozone, and nitrogen oxides $\left(\mathrm{NO}_{\mathrm{x}}=\mathrm{NO}+\mathrm{NO}_{2}\right)$. Measurements of $\mathrm{NO}_{2}$ in the troposphere are performed with various in-situ, airborne, and spaceborne instruments. Tropospheric vertical column densities (TVCD) retrieved from satellites (e.g. from the Scanning Imaging Absorption Spectrometer for Atmospheric Chartography (SCIAMACHY), the Global Ozone Monitoring Experiment (GOME(-2)), or the Ozone Monitoring Instrument (OMI)) have largely contributed to a better understanding of the global distribution of $\mathrm{NO}_{2}$ as well as its sources and trends (e.g. Boersma et al., 2004; Richter et al., 2005; van der A et al., 2008; Zhou et al., 2012). The spatial resolution of satellite products on the order of multiple tens of kilometers is only sufficient to detect aggregate sources like entire cities (Beirle et al., 2011) and individual sources like emissions from power plants (Kim et al., 2006) or ships (Beirle et al., 2004) if they are sufficiently separated in space from other sources. Ground-based in-situ instruments, on the other hand, provide accurate and continuous trace gas 
measurements but lack of homogeneous geographical coverage. Airborne remote sensing observations can in this regard provide a valuable link between ground-based and spaceborne $\mathrm{NO}_{2}$ information. For example, airborne multi-axis differential optical absorption spectroscopy (AMAXDOAS) was used to retrieve $\mathrm{NO}_{2}$ TVCD (Wang et al., 2005), $\mathrm{NO}_{2}$ profile information (Bruns et al., 2006), or to validate SCIAMACHY NO 2 TVCD (Heue et al., 2005). Heue et al. (2008) demonstrated the capability of an imaging DOAS instrument to retrieve two-dimensional $\mathrm{NO}_{2}$ distributions over the highly polluted Highveld plateau in South Africa.

The Airborne Prism EXperiment (APEX) imaging spectrometer is a state-of-the art instrument with an unprecedented combination of high spectral and spatial resolution, good two-dimensional geographical coverage, and high signal stability. Two $\mathrm{NO}_{2}$ distribution maps were retrieved from imaging spectrometer data acquired over Zurich, Switzerland, in the morning and the late afternoon of 26 June 2010. Our results are considered as one of the first spatio-temporal investigations of the $\mathrm{NO}_{2}$ distribution on a regional to local scale. In particular, we present the first high-resolution maps of $\mathrm{NO}_{2} \mathrm{VCD}$ in a city measured by an airborne imaging spectrometer. The specific objectives of this study are (i) the presentation of a retrieval scheme to obtain $\mathrm{NO}_{2}$ quantities from APEX imaging spectrometry data and (ii) the qualitative and quantitative assessment of the $\mathrm{NO}_{2}$ products, considering amongst others in-situ measurements of $\mathrm{NO}_{2}$.

\section{Instrument and data acquisition}

\subsection{The APEX instrument}

APEX is a dispersive pushbroom imaging spectrometer for environmental monitoring developed by a Swiss-Belgium consortium in the framework of the ESA-PRODEX programme (Itten et al., 2008). APEX consists of the imaging spectrometer itself, a Calibration Home Base (CHB) for instrument calibration, and a data processing and archiving facility (PAF) for operational product generation (Jehle et al., 2010). Table 1 gives a brief overview of the sensor characteristics.

The APEX imaging spectrometer consists of a CCD detector for the visible and near infrared (VNIR) and a CMOS detector for the shortwave infrared (SWIR) wavelength region. The $\mathrm{NO}_{2}$ retrieval is based on absorption bands in the UV/VIS spectral domain, and, hence, only the VNIR specification is discussed hereinafter. Since atmospheric trace gases exhibit spectrally narrow absorption features, the (spectrally) unbinned configuration was applied to provide highest spectral resolution. The spectral sampling interval (SSI) and the full width at half maximum (FWHM) are non-linear functions of the wavelength and increase with longer wavelengths. According to pre-flight sensor calibration, the SSI increases from 0.66 to $1.42 \mathrm{~nm}$ and the FWHM from 1.00 to
1.95 between $420 \mathrm{~nm}$ and $520 \mathrm{~nm}$ where $\mathrm{NO}_{2}$ slant column densities (SCD) are usually derived. APEX is a pushbroom scanner and measures radiances in 1000 spatial pixels acrosstrack. The extent of the flight line along-track depends on the pre-defined flight pattern. The spatial resolution in acrosstrack direction is determined by the sensor's instantaneous field of view (IFOV) of $0.028^{\circ}$. The spatial resolution alongtrack depends on the integration time. This unparalleled combination of high resolution, geographical coverage, and high signal stability makes APEX very attractive for a range of remote sensing applications, e.g. in the fields of vegetation, atmosphere, limnology, geology, or natural hazard studies.

\subsection{Test site and data}

APEX acceptance flight activities took place in Belgium and Switzerland in June/July 2010 using a Dornier Do-228 aircraft operated by the German Aerospace Center (DLR) (Jehle et al., 2010). Image data were collected in more than 42 flight hours for a variety of studies of the land-surface and the atmosphere. Six of these image data sets, acquired in unbinned mode over Zurich, Switzerland, on Saturday 26 June under cloud free conditions (cf. Fig. 1) were used in this study. Three of them were flown around 10:00 local time (08:00 UTC) and three in the late afternoon around 17:30 local time (15:30 UTC) at a cruise level of $5400 \mathrm{~m}$ above sea level (asl) and a flight heading of $45^{\circ}$ and $225^{\circ}$, respectively. The data integration time of APEX can be adjusted. The definition of an adequate integration time for the unbinned mode is, however, critical because the incoming radiation in the unbinned bands is comparatively small. An integration time of $57 \mathrm{~ms}$ was found to be a reasonable compromise between radiometric performance and the resulting pixel size of $2.5 \mathrm{~m}$ across-track and approximately $6 \mathrm{~m}$ along-track, respectively. This setting, in particular, ensures a sufficient signal stability in these spectral bands (i.e. the visible part from $370-500 \mathrm{~nm}$ ) and avoids signal saturation in other parts of the sampled spectrum (e.g. near infrared (NIR) from $700 \mathrm{~nm}$ onwards).

Zurich is Switzerland's largest city with about 400000 inhabitants surrounded by an agglomeration of more than one million inhabitants. The test site includes a wide range of surface types like buildings, roads, parks, forests, and part of Lake Zurich (Fig. 1, cf. also APEX true colour composite in Fig. 7a). It also includes more rural areas with decreased atmospheric pollution levels like the Uetliberg mountain range. Several major $\mathrm{NO}_{\mathrm{x}}$ sources were covered. Three national motorways surround the city to the north, west and south (A1, A3, A4), and major transit roads lead through the city with a usually high traffic volume. In addition, two waste incinerators as well as part of the approach corridor of Zurich airport are located in the test site area. Zurich was also selected for the flight experiments because of the dense ground-based air quality network with eight stations within the range covered by APEX (Fig. 1). The National Air Pollution Monitoring 
Table 1. Selected characteristics of the APEX imaging spectrometer.

\begin{tabular}{lrr}
\hline & VNIR & SWIR \\
\hline Spectral range & $380.5-971.7 \mathrm{~nm}$ & $941.2-2501.5 \mathrm{~nm}$ \\
Spectral bands & up to 334 & 198 \\
Spectral sampling interval & $0.55-8 \mathrm{~nm}$ & $5-10 \mathrm{~nm}$ \\
Spectral resolution (FWHM) & $0.6-6.3 \mathrm{~nm}$ & $6.2-11 \mathrm{~nm}$ \\
Spatial pixels (across track) & \multicolumn{2}{c}{1000} \\
Field of view & $28^{\circ}$ \\
Instantaneous field of view & $0.028^{\circ}(\sim 0.5 \mathrm{mrad})$ \\
Spatial sampling interval (across track) & $2.5 \mathrm{~m}$ at $5000 \mathrm{~m} \mathrm{AGL}$ \\
\hline
\end{tabular}

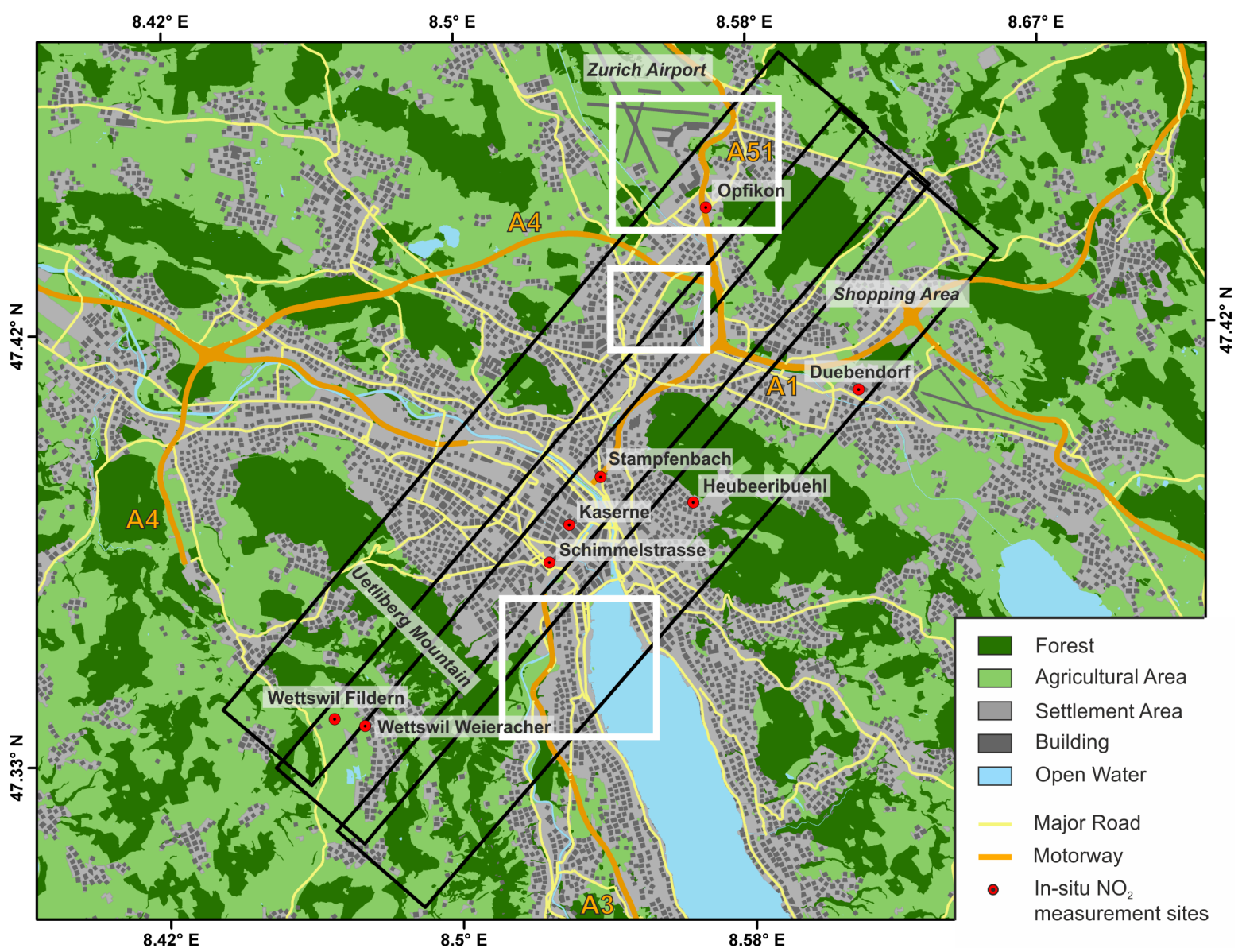

Fig. 1. Map of Zurich and surrounding areas (data source: Bundesamt für Landestopographie (Swisstopo)). The three morning flight lines are overlayed in black (the afternoon flight lines are almost identical and therefore omitted for clarity). The three white boxes correspond to the position of the examples shown in detail in Fig. 13. An APEX true colour composite corresponding to this flight lines is provided in Fig. 7a.

Network (NABEL) provides half-hourly averaged measurements of classical air pollutants like $\mathrm{NO}_{2}, \mathrm{O}_{3}, \mathrm{SO}_{2}, \mathrm{PM}_{10}$ at Zurich Kaserne (urban background, situated in a park near the city center) and Duebendorf (suburban). Additional air quality measurements and meteorological parameters are available from the inter-cantonal network OSTLUFT which maintains eight sites in the area of interest from which six sites provided data for 26 June 2010: Heubeeribuehl (periphery), Wettswil Filderen (rural, close to motorway), Wettswil Weieracher (rural), Stampfenbach (urban, kerbside, moderate traffic), Schimmelstrasse (urban kerbside, high traffic volume), and Opfikon (kerbside, motorway). 


\subsection{Data preparation}

APEX data were acquired in unbinned mode to provide highest spectral resolution. This instrumental setting, however, is at the expense of the signal stability. To increase the signalto-noise ratio (SNR), the imaging spectrometer data were spatially aggregated. A box size of $20 \times 20$ pixels was applied which is expected to increase the SNR 20 times (or $\sqrt{400}$ ) assuming uncorrelated noise. An image-based SNR estimation applied to the original unbinned APEX data revealed a SNR of 158.5 at $490 \mathrm{~nm}$ for dark surfaces (water). Spatial aggregation, hence, increases the SNR to approximately 3170 for dark surfaces. It is relevant to note that image-based SNR estimates usually overestimate noise or underestimate the SNR respectively, as surface variability is inherent in the image statistics. The spatial averaging resulted in a decreased pixel size of around $50 \times 120 \mathrm{~m}^{2}$.

The APEX spectrometer is spectrally and radiometrically calibrated pre-flight. However, it is worth mentioning that this calibration does not compensate for certain effects occurring in-flight. For example, pushbroom sensors are typically affected by slight spectral misregistrations across-track, e.g. spectral smile effects (D'Odorico et al., 2010) which may depend on the specific flight conditions. In order to minimize these effects, the $\mathrm{NO}_{2}$ retrieval was performed on geometrically uncorrected data to allow a scan-line by scan-line wise processing of the data. In addition, $\mathrm{NO}_{2}$ is determined from raw data (digital numbers or DN) and a spectral calibration is performed directly as part of the retrieval algorithm to account for spectral effects under flight conditions (cf. Sect. 3.1).

In order to obtain surface reflectance as an important input parameter of the retrieval algorithm, a software binning was applied to transform the unbinned data to the standard binning pattern and the data were subsequently calibrated to at-sensor radiance using the APEX-PAF. The re-binned radiance data were then atmospherically corrected using the ACTOR-4 software tool (Richter and Schläpfer, 2002) to obtain hemispherical-conical-reflectance (HCRF) data. In a last step, the unbinned and binned APEX data were geometrically corrected using the PARGE orthorectification software (Schläpfer and Richter, 2002). This processing step is needed to re-project auxiliary data (e.g. a digital elevation model (DHM25, http://www.swisstopo.admin.ch/ internet/swisstopo/en/home/products/height/dhm25.html,

last access: 12 March 2012)) to the raw geometry of the APEX data to allow a scan-line by scan-line wise processing as mentioned before. Further, the geocorrected data are essential to relate the APEX $\mathrm{NO}_{2}$ vertical column density (VCD) to the in-situ measurements of $\mathrm{NO}_{2}$ concentrations and to identify objects of interest like large $\mathrm{NO}_{\mathrm{x}}$ point sources.

\section{$3 \quad \mathrm{NO}_{2}$ retrieval}

The derivation of $\mathrm{NO}_{2}$ maps from APEX follows the two step approach usually applied to satellite $\mathrm{NO}_{2}$ retrievals. In a first step, differential slant column densities (dSCD) are derived by the well-known differential optical absorption spectroscopy (DOAS) technique (Platt and Stutz, 2008). Subsequently, the dSCD are converted to VCD by means of air mass factors (AMFs) calculated with a radiative transfer model. Detailed information about the physical principles, applications, and accuracies of DOAS and AMF computations can be found elsewhere (Palmer et al., 2001; Boersma et al., 2004; Platt and Stutz, 2008).

\subsection{DOAS analysis}

Differential slant column densities (dSCD) were derived with the QDOAS software (http://uv-vis.aeronomie. be/software/QDOAS/, last access: 12 March 2012, Fayt et al., 2011). DOAS analysis requires reference spectra which we obtained from the imaging spectrometer data themselves. Earthshine reference spectra were selected for each individual column of each overflight separately. This results in 50 different reference spectra per overflight and allows minimizing errors in the DOAS analysis caused by spectral miscalibration (e.g. spectral smile) and optical imaging imperfection. Based on visual inspection, areas in the individual overflights were determined which are assumed to only contain a background abundance of $\mathrm{NO}_{2}$ (pollution free), cf. in the forested and elevated area to the south of the city (Fig. 7a). The highlighted areas span over ten rows which were additionally averaged in the columnar direction to increase the SNR of the reference spectra.

$\mathrm{NO}_{2}$ absorption cross sections (at $293 \mathrm{~K}$, Voigt et al., 2002) were subsequently fitted to the differential optical depth derived from the APEX measurements and the reference spectra. Spectrally slowly varying signatures (e.g. from aerosols or surface reflectance) were accounted for by including a fifth-order polynomial in the fit, and instrumental effects such as dark current and/or straylight are dealt with in QDOAS by introducing an offset spectrum. Inelastic Raman scattering was considered by a ring cross section computed by QDOAS (cf. Fayt et al., 2011), and the interference with $\mathrm{O}_{2}-\mathrm{O}_{2}$ was accounted for by fitting an appropriate absorption cross section (Hermans et al., 2002). Smallest fitting errors were found by using the $470-510 \mathrm{~nm}$ wavelength region (c.f. red rectangle in Fig. 2). The usage of a window at shorter wavelengths (e.g. $420-470 \mathrm{~nm}$ ) led to increased fitting errors, probably due to the lower signal levels and higher noise. We also tested integrating $\mathrm{O}_{3}$ and $\mathrm{H}_{2} \mathrm{O}$ absorption in the DOAS fit which led to distinctly worse results probably due to a too small fitting window relative to the number of cross sections. Retrieved slant $\mathrm{O}_{3}$ and $\mathrm{H}_{2} \mathrm{O}$ columns reached unrealistic values and were correlated $\left(\mathrm{O}_{3}\right)$ 


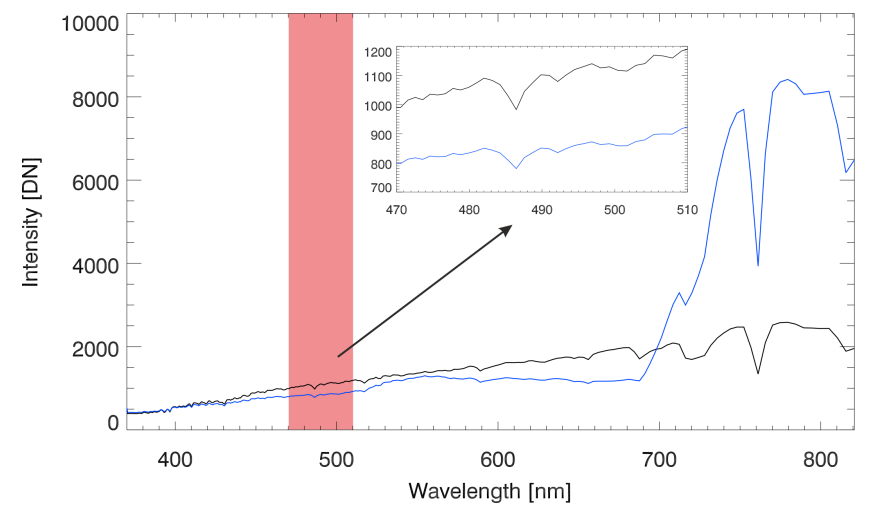

Fig. 2. Exemplary APEX spectra from the VIS/NIR detector acquired 26 June 2010 over Zurich, Switzerland. These particular spectra were recorded over a residential area in the eastern part of the city (black line) and over a remote vegetated area (blue line). The red rectangular overlay indicates the $\mathrm{NO}_{2}$ fitting window where a zoom-in of the two spectra is also provided.

or anti-correlated $\left(\mathrm{H}_{2} \mathrm{O}\right)$ with $\mathrm{NO}_{2}$. These interfering gases were therefore omitted hereinafter.

Accurate wavelength calibration is an important prerequisite for the DOAS analysis. As indicated above, raw DN (digital number) data were used to keep the highest sensitivity of the measurements for the $\mathrm{NO}_{2}$ retrieval. The spectral calibration was therefore performed with the QDOAS algorithm itself. A high-resolution solar spectrum (Chance and Kurucz, 2010) was applied to obtain spectral calibration information which was subsequently used to convolve and shift the high-resolution absorption cross sections to the APEX specifications. Two exemplary (pre-processed) APEX spectra from the VNIR detector recorded over a residential and a remote vegetated area are illustrated in Fig. 2. The corresponding slant column fit of the pixel over the residential area is presented in Fig. 3 which also gives an impression of the sensor's spectral resolution. The quality of the DOAS fit depends on the spectral and radiometric characteristics of the instrument. The spectral calibration step in QDOAS disclosed some differences to the pre-flight reported APEX specifications (Sect. 2.1 and Table 1) in the 470$510 \mathrm{~nm}$ wavelength range. The DOAS analysis indicated that the individual channels are positioned roughly $0.6 \mathrm{~nm}$ higher than reported pre-flight and the (over wavelength) averaged across-track difference of their corrected position (spectral smile) is $\sim 0.25 \mathrm{~nm}$. This is in line with recent findings from an in-flight and scene-based APEX performance assessment (D'Odorico et al., 2011). Furthermore, the QDOAS wavelength calibration and slit function characterisation point to a FWHM about double the spectral resolution measured in the laboratory at the CHB. The reasons for this discrepancy are not fully understood yet, and further analysis is currently being carried out. It is noteworthy that this increase in FWHM on the other hand reduces problems associated with spectral

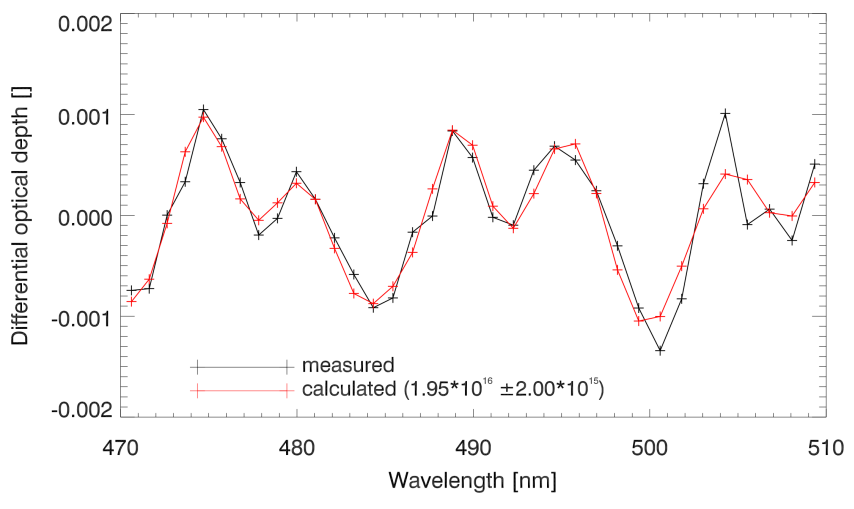

Fig. 3. Exemplary $\mathrm{NO}_{2}$ fit for an APEX spectrum recorded over Zurich (for the pixel shown in black in Fig. 2). The RMS of the residuals of this fit is $2.61 \times 10^{-4}$.

undersampling expected for the smaller spectral resolution defined in the pre-flight specification. Finally, note that negative dSCD can occur when the SCD from the reference spectrum is larger than that from the fitted spectrum or due to noise.

\subsection{Air mass factor calculation}

The AMF expresses the ratio between slant and vertical column of a trace gas:

$\mathrm{SCD}=\mathrm{VCD} \times \mathrm{AMF}$

and is a measure of the average backscatter path through the atmosphere of the photons observed by the sensor. The AMF can be calculated as follows (Palmer et al., 2001; Boersma et al., 2004):

$\mathrm{AMF}=\frac{\sum m_{\mathrm{L}}(\hat{b}) x_{\mathrm{a}, \mathrm{L}}}{\sum x_{\mathrm{a}, \mathrm{L}}}$

where the subscript $L$ denotes a specific atmospheric layer and $m_{\mathrm{L}}$ is the (box) air mass factor per layer. Besides the layer subcolumns of the a priori $\mathrm{NO}_{2}$ profile $\left(x_{\mathrm{a}, \mathrm{L}}\right)$, the AMF depends on forward model parameters $(\hat{b})$ such as the solar and viewing zenith and azimuth angles, surface reflectance, aerosol extinction profile, and surface pressure. The box air mass factors were calculated using the linearized discrete ordinate radiative transfer model (LIDORT, Spurr, 2008):

$m_{\mathrm{L}}=-\frac{1}{I} \frac{\partial I}{\partial \tau_{\mathrm{L}}}$

where $I$ is the intensity of the backscattered radiance and $\tau_{\mathrm{L}}$ the optical depth of layer $L$.

With regard to radiative transfer computations, the surface reflectance for every pixel was derived from re-binned and atmospherically corrected APEX data themselves for the central wavelength of the fitting window $(490 \mathrm{~nm})$. Surface height was taken from the digital elevation model 


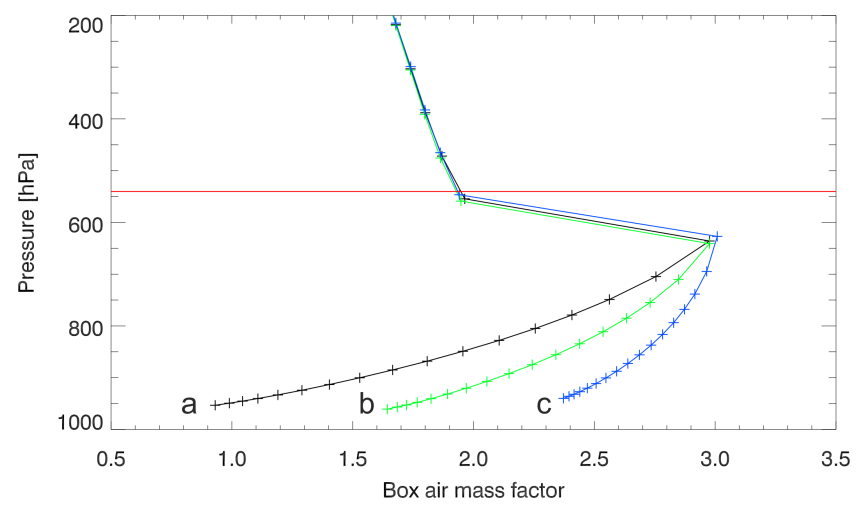

Fig. 4. Three exemplary box air mass factor curves from the APEX $\mathrm{NO}_{2}$ VCD retrieval. Curve (a) represents a pixel with surface albedo (at $490 \mathrm{~nm}$ ) of 0.05 , (b) of 0.12 , and (c) of 0.27 leading to AMFs of 1.46 (a), 1.98 (b), and 2.52 (c), respectively. Note that also additional parameters such as surface pressure or observation geometry vary thereby introducing small differences between the three box air mass factor profiles. The horizontal red line depicts the flight altitude.

DHM25 previously projected to the raw geometry of the individual flight lines. Surface pressure for every pixel was subsequently obtained applying the US Standard Atmosphere 1976 (http://www.pdas.com/coesa.html, last access: 12 March 2012). The a priori $\mathrm{NO}_{2}$ profile was taken from the EURAD chemical transport simulations (http:// www.eurad.uni-koeln.de/, last access: 12 March 2012) over Switzerland at $5 \times 5 \mathrm{~km}^{2}$. The coarse resolution profile was subsequently scaled to the corresponding surface height of the aggregated APEX grid cell according to Zhou et al. (2009). Aerosol optical depth (AOD) at $500 \mathrm{~nm}$ was taken from the Aerosol Robotic Network (AERONET, Holben et al., 1998) site Laegeren which is approximately $20 \mathrm{~km}$ from the city of Zurich. The AOD was converted to an extinction profile for every pixel assuming an exponential decrease with height and a scale height of two kilometers. The box air mass factors from three exemplary (aggregated) APEX pixels are depicted in Fig. 4. APEX's sensitivity toward a $\mathrm{NO}_{2}$ signal is highest in the atmospheric layer below the aircraft (red horizontal line) and is decreasing toward the surface and toward higher atmospheric layers. Among all the above-mentioned parameters, the surface albedo has the largest impact on the AMF. For example, the bright surface (albedo of 0.27) of case (c) in Fig. 4 highly increases the APEX sensitivity toward surface $\mathrm{NO}_{2}$. This is supported by Fig. 5 which displays the computed AMF versus surface albedo from the easterly morning flight line and which emphasizes the importance of a good quality surface albedo data set in our $\mathrm{NO}_{2} \mathrm{VCD}$ determination.

Since we are using earthshine spectra as reference, the results of the DOAS fit are differential slant column densities

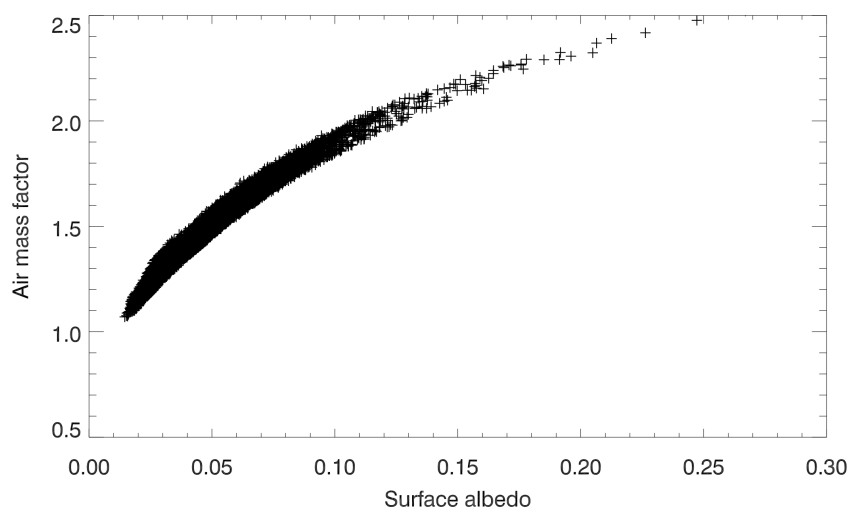

Fig. 5. Plot of the air mass factors versus their corresponding surface albedo from the easterly flight line in the morning.

$\left(\mathrm{dSCD}=\mathrm{SCD}_{\mathrm{P}}-\mathrm{SCD}_{\mathrm{R}}\right)$ which can be written as

$$
\begin{aligned}
\mathrm{dSCD} & =\left(\mathrm{VCD}_{\mathrm{P}} \times \mathrm{AMF}_{\mathrm{P}}+\mathrm{SCD}_{\mathrm{STR}}\right) \\
& -\left(\mathrm{VCD}_{\mathrm{R}} \times \mathrm{AMF}_{\mathrm{R}}+\mathrm{SCD}_{\mathrm{STR}}\right)
\end{aligned}
$$

where the subscripts $P$ and $R$ refer to tropospheric quantities under polluted and clean (reference) conditions, respectively. The stratospheric contribution to dSCD can reasonably be assumed to be constant for the polluted and reference spectra in our study region. Hence, the (additive) stratospheric SCD ( $\mathrm{SCD}_{\mathrm{STR}}$ ) cancels out on the right hand side of Eq. (4) and $\mathrm{AMF}_{\mathrm{P}}$ and $\mathrm{AMF}_{\mathrm{R}}$ are calculated using only atmospheric levels up to the tropopause in Eq. (2). Rearranging Eq. (4) finally yields the VCDP:

$\mathrm{VCD}_{\mathrm{P}}=\frac{\mathrm{dSCD}+\mathrm{VCD}_{\mathrm{R}} \times \mathrm{AMF}_{\mathrm{R}}}{\mathrm{AMF}_{\mathrm{P}}}$

where the $\mathrm{VCD}_{\mathrm{R}}$ has to be estimated. In our case we assume $1 \times 10^{15} \mathrm{molec} \mathrm{cm}^{-2}$ which is in the range of previously reported rural/background tropospheric columns for European summer conditions from OMI data and an ensemble of regional air quality models (Huijnen et al., 2010). Note that dSCD varies primarily due to different $\mathrm{NO}_{2}$ below the aircraft, mainly in the boundary layer where $\mathrm{NO}_{2}$ profiles usually peak close to the source. Free tropospheric $\mathrm{NO}_{2}$ and particularly the tropospheric $\mathrm{NO}_{2}$ above the aircraft is expected to contribute only very little as it is probably similar for the reference and sample observations, and in addition the $\mathrm{NO}_{2}$ concentrations and above-aircraft AMF values are low.

\subsection{Post-processing}

Missing pixels due to a failed dSCD fit were replaced with the mean $\mathrm{NO}_{2} \mathrm{VCD}$ value of the nearest neighbours (less than $5 \%$ of all retrievals were affected). The resulting $\mathrm{NO}_{2}$ maps were subsequently de-striped in order to correct for artefacts introduced by parameters varying (randomly) across-track, e.g. the reference VCD or remaining 
sensor artefacts. Assuming that $\mathrm{NO}_{2} \mathrm{VCD}$ averaged in alongtrack (column) direction varies smoothly across-track (row), a fifth degree polynomial was fitted to the column averages. The residuals per column were finally subtracted from the initially retrieved $\mathrm{NO}_{2} \mathrm{VCD}$ field.

\section{Results}

The capability of APEX to sense $\mathrm{NO}_{2}$ and the $\mathrm{NO}_{2}$ product itself are assessed and discussed in the following subsections. The $\mathrm{NO}_{2} \mathrm{SCD}$ fitting and the two-dimensional VCD distribution are analyzed in detail. Further, the APEX $\mathrm{NO}_{2}$ maps are compared with ground-based in-situ measurements and yearly averaged modelled $\mathrm{NO}_{2}$ surface concentration fields.

\subsection{SCD analysis}

Histograms of derived $\mathrm{NO}_{2}$ dSCD and the corresponding dSCD error are depicted in Fig. 6. Selected statistical parameters obtained by the DOAS analysis can be found in Table 2. The average dSCD for the morning flight lines is $9.2 \times 10^{15} \mathrm{molec} \mathrm{cm}^{-2}\left( \pm 8.31 \times 10^{15}\right.$ molec cm $\left.{ }^{-2}\right)$ which is about 2.5 times higher than the average dSCD of the afternoon flights $\left(3.87 \times 10^{15}\right.$ molec $\mathrm{cm}^{-2} \pm 5.09 \times 10^{15}$ molec $\mathrm{cm}^{-2}$ ). The minimum dSCD is on the same order for both overflight times $\left(-1.58 \times 10^{16}\right.$ molec $\mathrm{cm}^{-2}$ and $-1.68 \times 10^{16}$ molec $\mathrm{cm}^{-2}$, respectively), whereas the maximum dSCD for the morning is almost twice the afternoon value $\left(4.71 \times 10^{16}\right.$ molec cm $\mathrm{cm}^{-2}$ versus $2.86 \times 10^{16} \mathrm{molec}$ $\mathrm{cm}^{-2}$ ). Several random and systematic error sources affect the APEX-based dSCD fitting, e.g. instrumental noise, wavelength calibration, or temperature dependency of the absorption cross sections (Boersma et al., 2004). A detailed assessment of these error sources is beyond the scope of this study. Rather, we concentrate here on the overall dSCD error. About $14 \%$ of all retrievals lead to negative dSCD for the morning overflight and $22 \%$ for the afternoon overflight (Table 2). The averaged fitting error for the morning is $2.37 \times 10^{15} \mathrm{molec} \mathrm{cm}^{-2}\left( \pm 6.47 \times 10^{14} \mathrm{molec} \mathrm{cm}^{-2}\right)$ and for the afternoon $2.42 \times 10^{15}$ molec $\mathrm{cm}^{-2}\left( \pm 4.53 \times 10^{14} \mathrm{molec}\right.$ $\mathrm{cm}^{-2}$ ). This corresponds to $24 \%$ and $47 \%$ of the respective absolute dSCD. The absolute dSCD fitting errors and their standard deviations are very similar for the morning and afternoon results. In general, the dSCD errors do not reveal any geographical pattern (not shown) like e.g. correlation with albedo or surface type. SCD errors on the order of $0.7 \times 10^{15}$ molec $\mathrm{cm}^{-2}$ are reported for different satellite $\mathrm{NO}_{2}$ retrievals in the literature (Boersma et al., 2004, 2007; Valks et al., 2011; Valin et al., 2011). These lower SCD errors can be explained by the better characteristics of these sensors specifically designed for trace gas remote sensing (e.g. SSI, FWHM, SNR, fitting window at shorter wavelength with stronger $\mathrm{NO}_{2}$ signal possible) as compared to APEX (cf. Sect. 2.1 and Table 1).

\section{2 $\mathrm{NO}_{2}$ spatial distribution}

The spatial distributions of $\mathrm{NO}_{2} \mathrm{VCD}$ over Zurich for the morning and afternoon overflights are depicted in Fig. 7b and c, respectively. In addition, a comparison between the morning APEX $\mathrm{NO}_{2} \mathrm{VCD}$ and modelled yearly averages of surface $\mathrm{NO}_{2}$ concentrations for 2010 is presented in Fig. 8 . The simulation is based on a high-resolution $\left(100 \times 100 \mathrm{~m}^{2}\right)$ emission inventory combined with a Gaussian plume dispersion model (SAEFL, 2004). Overall, APEX $\mathrm{NO}_{2} \mathrm{VCD}$ are considerably higher for the morning than for the afternoon overflights. Especially the morning mosaic of the three flight lines reveals very distinct and plausible spatial $\mathrm{NO}_{2}$ patterns. Higher $\mathrm{NO}_{2} \mathrm{VCD}$ can be found in residential areas (specifically over the city), over motorways, and around the international airport of Zurich to the north of the scene. Interestingly, the enhanced $\mathrm{NO}_{2} \mathrm{VCD}$ values in the northeastern part of the scene correspond to a large shopping area west of the motorway A4 (cf. Fig. 1) which is known to have a large traffic volume during shopping hours, especially on Saturdays. Higher $\mathrm{NO}_{2}$ in the southwestern part of the image area corresponds to a motorway junction where three motorway tunnels intersect open air. In general, the motorways as a prominent source of $\mathrm{NO}_{2}$ do not show up as clearly in the APEX NO$~_{2}$ VCD maps as in the model surface $\mathrm{NO}_{2}$ (Fig. 8). One has to consider that these data were acquired on a Saturday where traffic reveals different characteristics than during weekdays, e.g. generally less traffic volume with more private transport, less commuter traffic, and fewer trucks. Lower $\mathrm{NO}_{2}$ mainly occurs in remote and/or forested areas, e.g. at the Uetliberg mountain range to the south-west of the city or the forested area just east of the airport. Further, the three different flight lines per mosaic generally superimpose well. This is underlined by Fig. 9 which shows the N-S transects of the APEX $\mathrm{NO}_{2}$ VCD in the overlapping region (cf. map in Fig. 1) of the central and eastern morning overpasses. The two curves are in very good agreement with a correlation coefficient of around 0.95. However, the values from the central line are biased against the eastern line. The mean difference between these two curves is around $1.9 \times 10^{15}$ (or $28 \%$ ) which might be due to several reasons. For example, the $\mathrm{NO}_{2}$ columns in the "pollution-free" areas where the reference spectra are selected can slightly differ due to terrain variations such that using reference spectra from lower altitudes (higher $\mathrm{NO}_{2}$ columns) leads to relatively lower $\mathrm{NO}_{2}$ VCD than those from higher altitudes. In addition, the two flight lines do not observe exactly the same air mass at the same location due to the varying observation geometry and the time lag between the two measurements.

Overall, the spatial $\mathrm{NO}_{2}$ distribution and the abovementioned $\mathrm{NO}_{2}$ features are in good agreement with the modelled surface concentration in Fig. 8 underlying the capability of APEX to detect tropospheric $\mathrm{NO}_{2}$. It should be kept in mind that the APEX data represent the $\mathrm{NO}_{2}$ distribution at a given time under a specific weather situation while the 
Table 2. Statistics for the $\mathrm{NO}_{2}$ VCD retrievals from the morning and afternoon overflight $(\mathrm{OF}=$ overflight, Av. $=$ average, Stddev $=$ standard deviation). The units are molecules $\mathrm{cm}^{-2}$ where not otherwise indicated.

\begin{tabular}{lccccccc}
\hline & $\begin{array}{c}\text { Av. } \\
\text { dSCD }\end{array}$ & $\begin{array}{c}\text { Stddev } \\
\text { dSCD }\end{array}$ & $\begin{array}{c}\text { Min } \\
\text { dSCD }\end{array}$ & $\begin{array}{c}\text { Max } \\
\text { dSCD }\end{array}$ & $\begin{array}{c}\text { Av. } \\
\text { dSCD error }\end{array}$ & $\begin{array}{c}\text { Stddev } \\
\text { dSCD error }\end{array}$ & $\begin{array}{c}\% \text { negative } \\
\text { dSCD }\end{array}$ \\
\hline Morning OF & $9.20 \times 10^{15}$ & $8.31 \times 10^{15}$ & $-1.58 \times 10^{16}$ & $4.71 \times 10^{16}$ & $2.37 \times 10^{15}(24 \%)$ & $6.47 \times 10^{14}$ \\
Afternoon OF & $3.87 \times 10^{15}$ & $5.09 \times 10^{15}$ & $-1.68 \times 10^{16}$ & $2.86 \times 10^{16}$ & $2.42 \times 10^{15}(47 \%)$ & $4.53 \times 10^{14}$ & 22 \\
\hline
\end{tabular}
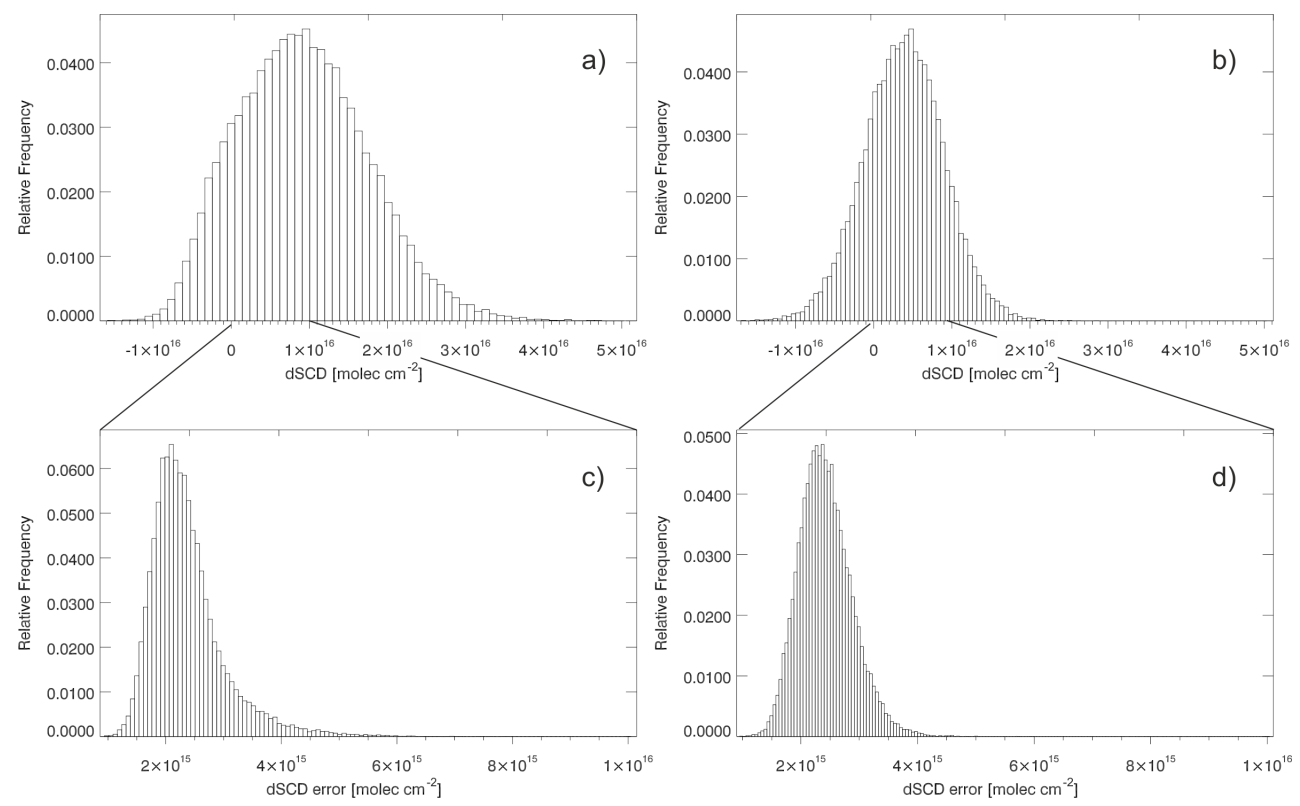

Fig. 6. Histograms of dSCD (upper panel) and dSCD errors (lower panel) for the morning (left panel) and afternoon (right panel) APEX flights. Note the much shorter scale of the $\mathrm{x}$-axis in the lower panel.

model distribution is an annual mean estimate. APEX data also represent vertical below-aircraft columns, whereas the model data are concentrations at the surface. A closer look at some exemplary and specific areas is given in Sect. 4.3.

Differential SCD, AMF as well as the VCD are illustrated in Fig. 10 for the central morning flight stripe. As already underlined by Fig. 5, the surface reflectance has the largest impact on the AMF. For example, the lowest AMF values can be found over the dark forested areas and the highest ones over man-made structures such as buildings and roads. In our study region, therefore, significant correlation between bright surfaces and enhanced $\mathrm{NO}_{\mathrm{x}}$ due to emissions from motorways and residential or industrialized areas can be found. Darker surfaces, in contrast, corresponded to comparatively clean vegetated areas. Without accounting for the varying surface reflectance, the contrast between polluted and clean areas would therefore be clearly overestimated. Figure 10 further demonstrates that spatially varying AMF also has an impact on small-scale $\mathrm{NO}_{2}$ features like e.g. in the lower (southern) part of the flight stripe around the in situ site Wettswil Filderen (cf. map in Fig. 1). However, overall the largest part of the VCD variability can clearly be linked to the variability of the dSCD.

In general, spatial gradients of $\mathrm{NO}_{2} \mathrm{VCD}$ are more pronounced for the morning, but enhanced $\mathrm{NO}_{2} \mathrm{VCD}$ around the airport, around the motorway junction, over the city and decreased $\mathrm{NO}_{2}$ VCD in remote areas and over the lake are also detectable in the afternoon maps.

The above-mentioned differences are due to the different meteorological conditions in the morning and afternoon which affected the transport and dilution of $\mathrm{NO}_{\mathrm{x}}$ downwind from its sources and possibly also its lifetime. The diurnal evolution of surface $\mathrm{NO}_{2}$ concentrations measured at eight NABEL and OSTLUFT sites is plotted in Fig. 11. The values during the APEX overflights range from low $\left(4.1 \mu \mathrm{g} \mathrm{m}^{-3}\right)$ to polluted $\left(43.55 \mathrm{~g} \mathrm{~m}^{-3}\right)$ depending on the location and time of day. All sites show a strong decrease of $\mathrm{NO}_{2}$ during the morning hours and more or less stable concentrations in the afternoon (after about 12:00 UTC). This behaviour is typical for sunny summer days and is to a large extent driven by the evolution of the boundary layer leading to decreased surface concentrations in the afternoon due to enhanced vertical mixing. However, variations in vertical mixing may not 


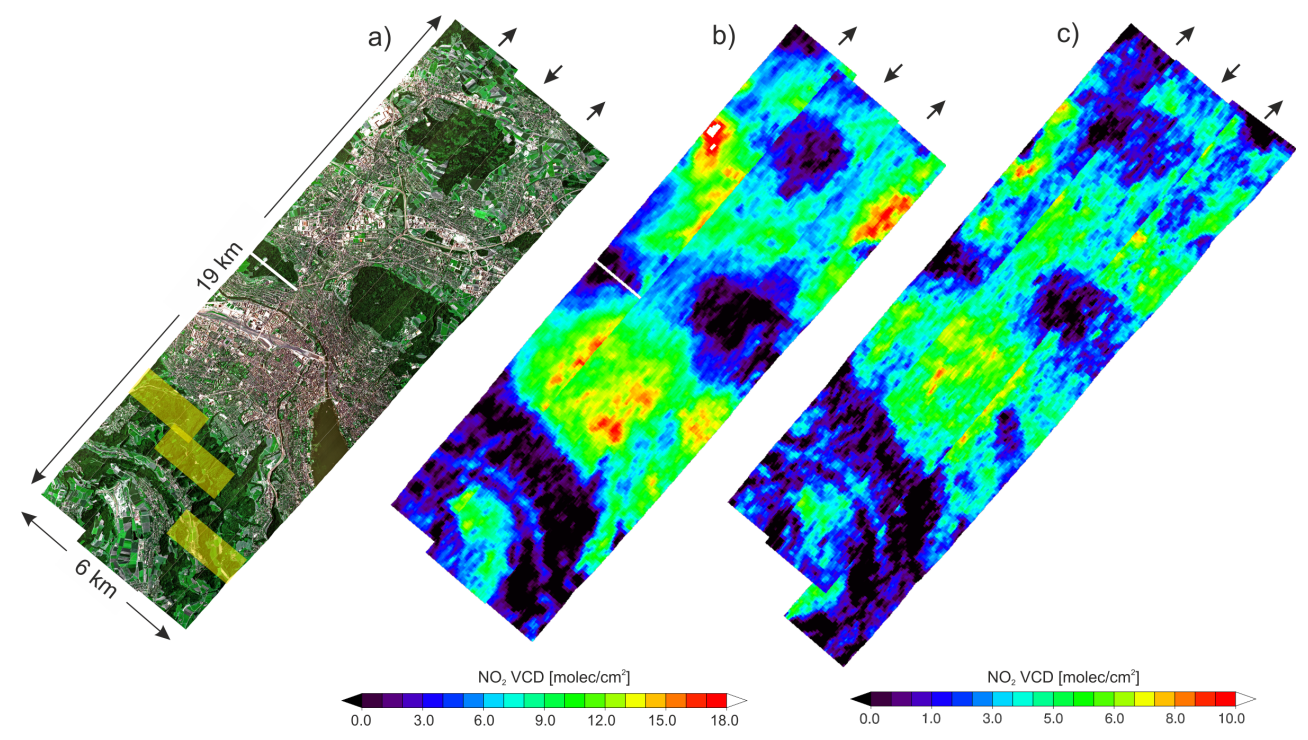

Fig. 7. RGB composite of the morning overflights (a) as well as retrieved $\mathrm{NO}_{2}$ VCD from the morning (b) and afternoon overflights (c). The morning data were recorded on 26 June 2010 around 10:00 local time (or 08:00 UTC) and the afternoon data the same day around 17:30 (or 15:30 UTC). The small arrows denote the heading of the aircraft for each flight line. The areas of each flight line where the reference spectra have been determined are denoted by the transparent yellow boxes in (a). Also note the different colour scale applied to (b) and (c).

a)

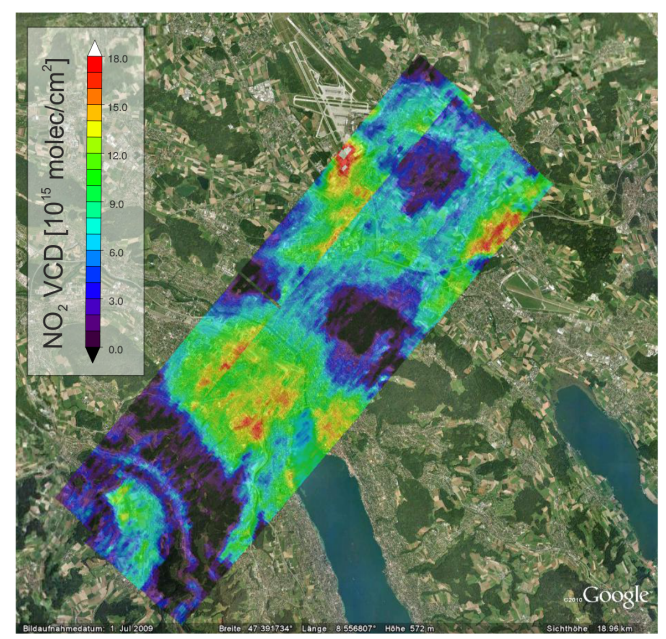

b)

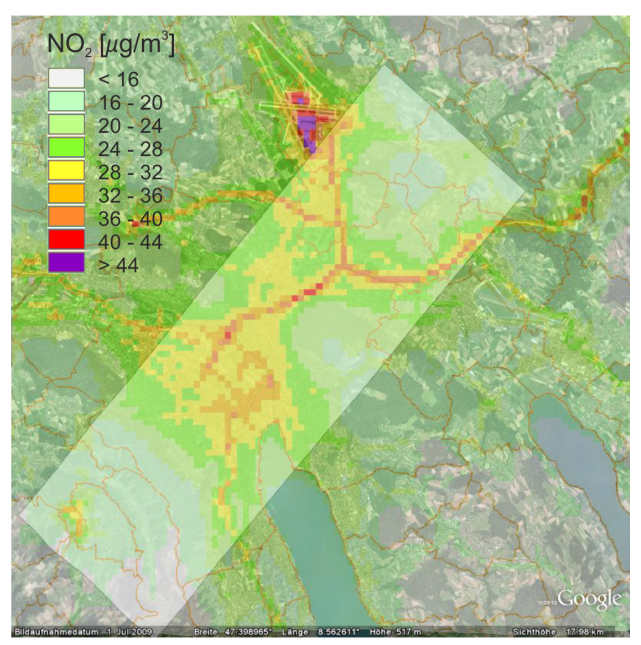

Fig. 8. Retrieved $\mathrm{NO}_{2}$ VCD from the morning overflights over Zurich (a). (b) illustrates the modelled yearly averages of surface $\mathrm{NO}_{2}$ concentrations (modelled for the year 2010 and available at: http://www.gis.zh.ch/gb4/bluevari/gb.asp?app=GB-LHNO210, last access: 12 March 2012). The thin orange lines in (b) depict district/community boundaries.

explain the differences in the vertical columns observed by APEX. One reason for lower VCD in the afternoon could be enhanced chemical loss of $\mathrm{NO}_{2}$ due to the reaction with the hydroxyl radical $(\mathrm{OH})$. However, since the solar zenith angle was approximately the same during the morning and afternoon overpasses and since $\mathrm{OH}$-levels depend on $\mathrm{NO}_{\mathrm{x}}$ concentrations in a strongly non-linear way (e.g. Jaeglé et al., 1998), it is not clear whether OH-levels were on average higher or lower in the afternoon.
A more likely explanation for the lower VCD in the afternoon is stronger dilution due to stronger winds. Wind speed and direction measured at two different sites maintained by the Swiss Federal Office of Meteorology and Climatology (Fig. 12) show that the meteorological situation changed distinctively shortly after the morning APEX flights, i.e. wind speed sharply increased by nearly four times until noon and the wind direction switched from northwest to northeast typical of a bise situation. The stronger winds lead to a stronger dilution and more rapid transport of $\mathrm{NO}_{2}$ to regions 


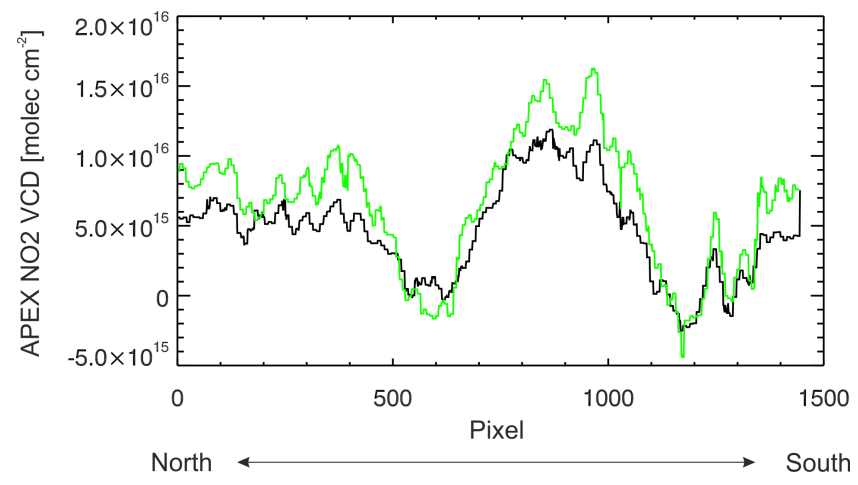

Fig. 9. North-south transect of retrieved $\mathrm{NO}_{2} \mathrm{VCD}$ of the overlapping region of the central (green line) and eastern (black line) morning overflights (the exact position can be found in the map in Fig. 1).
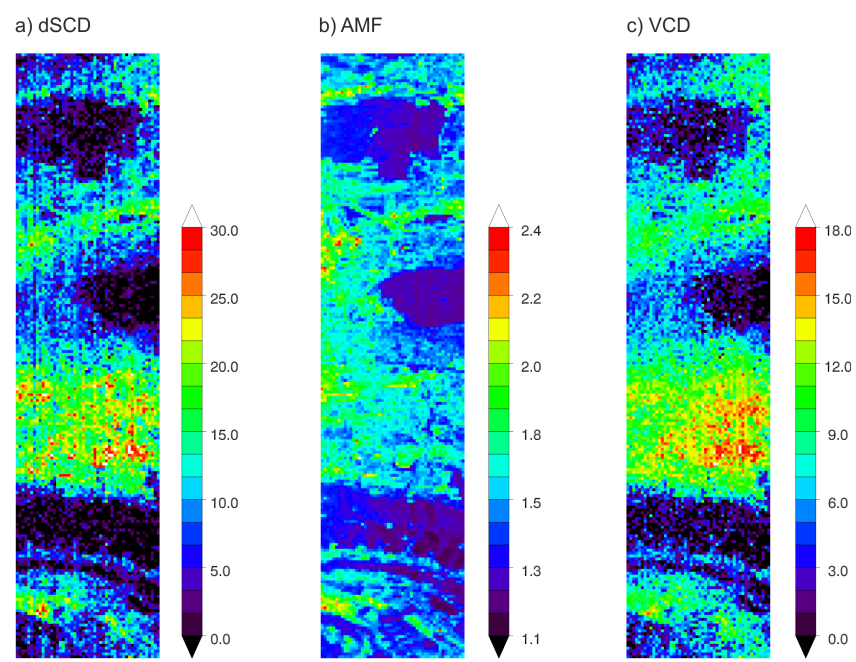

Fig. 10. Differential SCD (a), AMF (b), and VCD (c) of the central flight stripe from the morning overflights (cf. Figs. 7 and 8).

downwind of its main emission sources. The lower winds in the morning may also explain the larger $\mathrm{NO}_{2}$ variability and therewith better detectability of $\mathrm{NO}_{2}$ sources for the APEX sensor during the morning overflights. These meteorological conditions together with the diurnal cycle of $\mathrm{NO}_{2}$ are also of particular interest with regard to the planning of future flight campaigns.

Different parameters related to the sensor characteristic and retrieval algorithm may also partly account for the reported differences. The selected reference spectra should ideally be determined from a pollution-free area with a high albedo and therefore high SNR. However, such an ideal reference spectra could not be found in the current test area. The used reference spectra over a forested area characterized by a relatively low albedo might cause a decreased dSCD fitting quality (cf. Sect. 4.1). Further, the contrast in $\mathrm{NO}_{2}$ between the area where the reference spectra were chosen and the other areas is rather small for the afternoon case for reasons

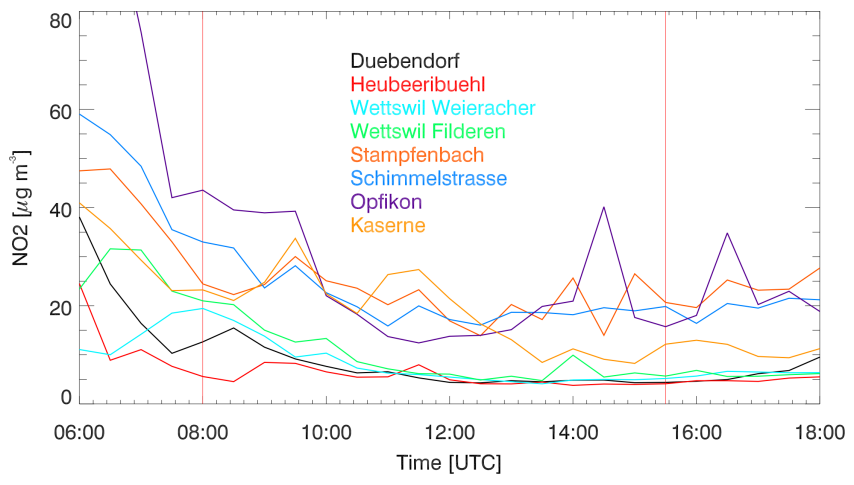

Fig. 11. Diurnal evolution of $\mathrm{NO}_{2}$ surface concentrations at eight monitoring sites in the study region. The two vertical red lines denote the time of the APEX overflights.

discussed above. This reduced contrast leads to distinctively more negative dSCD derived for the afternoon (cf. Sect. 4.1).

Forward model parameters vary during the course of the day and therewith also the AMF. The average AMF increased from 1.51 in the morning to 1.71 in the afternoon. The major part of this change can be assigned to an increase in the aerosol optical depth from 0.19 to 0.26 (at $500 \mathrm{~nm}$ ) based on sun photometer measurements from the nearby AERONET site Laegeren. The solar zenith angles were quite similar for the morning (at 08:00 UTC $\sim 48.2^{\circ}$ ) and afternoon (around 15:30 UTC $\sim 52.9^{\circ}$ ), but these differences nevertheless slightly affect the AMF. Uncertainties in $\mathrm{AMF}$ are known to be a major source of uncertainty in $\mathrm{NO}_{2}$ VCD retrievals. For example, several studies (Boersma et al., 2004, 2007; Zhou et al., 2010) estimated AMF uncertainties in the range of $30 \%$ for OMI and SCIAMACHY. A somewhat lower AMF uncertainty can be expected in the presented retrieval because we do not have to deal with cloud contamination which is an important part of the AMF uncertainty (Boersma et al., 2004; Popp et al., 2011). An additional influence on the accuracy of the AMF can be expected from retrieval input parameters with insufficient spatial resolution not matching the high resolution of APEX. Heckel et al. (2011), for example, studied the impact of coarseresolution retrieval input parameters (a priori $\mathrm{NO}_{2}$ profile, surface reflectance, and aerosol information) on satellite retrievals of tropospheric $\mathrm{NO}_{2} \mathrm{VCD}$ with significantly smaller pixel size. They identified the a priori profile and surface albedo to have the largest impact on the retrieval uncertainty. In our approach, we therefore derive the surface reflectance directly from the APEX data at high resolution. Profiles of $\mathrm{NO}_{2}$ and aerosols, on the other hand, are taken from coarseresolution data sets which represents an important remaining error source. For an improved retrieval and error quantification, future flight campaigns should therefore aim at flying vertical $\mathrm{NO}_{2}$ and aerosol profiles with complementary in situ instrumentation. Aerosol information (e.g. AOD) can potentially be derived from APEX data itself in the future (Seidel 


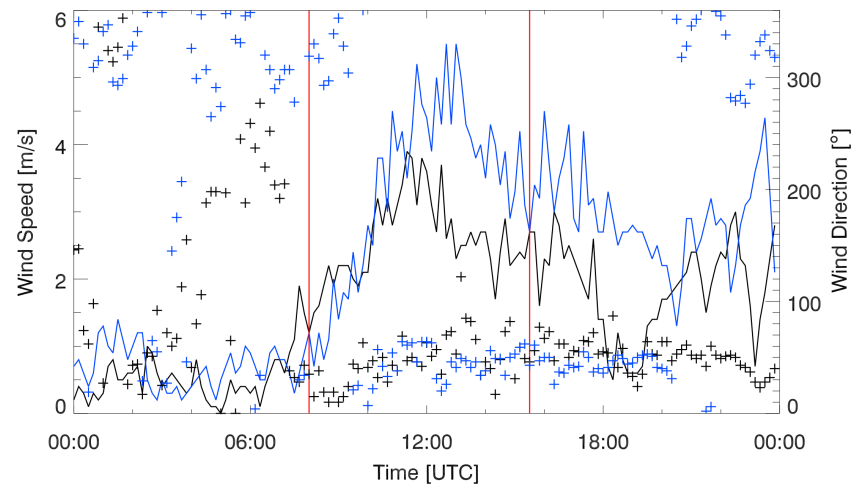

Fig. 12. Diurnal curve of wind speed (solid lines) and wind direction (crosses) at the two sites Zurich SMA (black) and Zurich Airport (blue) from measurements provided by the Swiss Federal Office of Meteorology and Climatology. The two vertical red lines denote the time of the APEX overflights.

et al., 2011). The high spatial resolution of the APEX data also has implications on the radiative transfer calculations. For example, photons from neighbouring pixels can be scattered into the instantaneous field-of-view. Considering such three-dimensional effects in the radiative transfer computations would potentially improve future $\mathrm{APEX} \mathrm{NO}_{2}$ retrievals.

\subsection{Examples of source identification}

A more detailed view of specific $\mathrm{NO}_{2}$ features detected by APEX is illustrated in the basis of three examples in Fig. 13 where the APEX VCD are shown in the left panel (Figs. 13a, d, g), the yearly averaged surface concentration in the middle panel (Figs. 13b, e, h), and some specific zoomins in the right panel (Figs. 13c, f, i). The first example (Fig. 13a and b) focuses on an area around the southeastern part of Zurich international airport. The enhanced surface $\mathrm{NO}_{2}$ concentrations around the end of the two runways are well captured by the APEX VCD map. These two features are most likely caused by emissions from aircraft landing and taking off. The aircrafts took off towards the south on 26 June 2010 (cf. http://www.flughafen-zuerich.ch, last access: 11 July 2012). The enhanced $\mathrm{NO}_{2} \mathrm{VCD}$ at the end of the north-south runway thus likely reflects the increased $\mathrm{NO}_{\mathrm{x}}$ emissions by aircraft during take-off. Additionally, the APEX RGB image (Fig. 13c) acquired in the morning shows different aeroplanes in motion around the hangar and one at the engine test stand (encircled red) close to the area of maximum $\mathrm{NO}_{2} \mathrm{VCD}$ in this example. In contrast, APEX VCD does not mirror the enhanced surface $\mathrm{NO}_{2}$ concentrations above the motorway A51 which might be explained by the different traffic characteristics on a Saturday morning. The second example (Fig. 13d and e) displays the area around the waste incinerator Hagenholz situated between the city and the airport (cf. map in Fig. 1). The plume of the waste incinerator pointing in the southwest direction does clearly emerge in the RGB subscene (Fig. 13f). The increased $\mathrm{NO}_{2}$ around the chimney (red and white areas) is well detectable in the APEX VCD maps while the representing surface concentrations does not reflect the emissions from this elevated source. The third example shows an area around the lower part of Lake Zurich, including the national motorway A3 and the harbour/dockyard at the shore of Lake Zurich. In general, the spatial gradients of the yearly average surface $\mathrm{NO}_{2}$ distribution are reproduced well by APEX VCD. Also the $\mathrm{NO}_{2}$ abundance from traffic emissions along the motorway A3 is detectable in this example. In contrast to the first example, this specific leg of the motorway A3 is located in a $\mathrm{N}-\mathrm{S}$ oriented valley, which likely channelled emitted $\mathrm{NO}_{2}$. The smeared-out patterns of $\mathrm{NO}_{2}$ over and around the lake basin are a result of locally transported $\mathrm{NO}_{2}$. The $\mathrm{NO}_{2}$ hot spot in the southern part of example three is situated over the harbour/dockyard area of Zurich. The APEX RGB image (Fig. 13i) shows a vessel on the ramp of the dockyard during the morning overflight. However, if specific engine tests were performed or not is unknown.

\subsection{Comparison to ground-based measurements}

The APEX-derived $\mathrm{NO}_{2} \mathrm{VCD}$ are subsequently compared to the ground-based in situ measurements. Such a comparison is not straightforward since APEX $\mathrm{NO}_{2} \mathrm{VCD}$ is a columnar product (in molec $\mathrm{cm}^{-2}$ ) while the in-situ measurements represent a trace gas concentration at a single point (in $\mu \mathrm{g} \mathrm{m}^{-3}$ ). Therefore, we convert the in situ measured concentrations to an "in situ VCD" ( $\left.\mathrm{VCD}_{\mathrm{IS}}\right)$ assuming that the a priori $\mathrm{NO}_{2}$ profile correctly described the true $\mathrm{NO}_{2}$ profile:

$\mathrm{VCD}_{\mathrm{IS}}=\frac{\mathrm{VCD}_{\mathrm{AP}} \times \mathrm{NO}_{2 \mathrm{IS}}}{\mathrm{NO}_{2_{\mathrm{AP}}}}$

where $\mathrm{VCD}_{\mathrm{AP}}$ is the total of the sub-columns of the a priori $\mathrm{NO}_{2}$ profile from the ground to the flight altitude, $\mathrm{NO}_{2 \mathrm{IS}}$ the concentration measured at the ground and $\mathrm{NO}_{2 \mathrm{AP}}$ the concentration of the a priori profile in the lowest layer.

The comparison is shown in Fig. 14 where the APEX retrieved $\mathrm{NO}_{2} \mathrm{VCD}$ are plotted as a function of the $\mathrm{VCD}_{\mathrm{IS}}$ at the eight NABEL and OSTLUFT sites. The Pearson correlation coefficients for the morning and afternoon results separately are almost identical $(R=0.61)$ suggesting that the variability between the in situ sites corresponds to some extent to the spatial pattern observed by APEX. When disregarding the match-ups corresponding to the in situ sites located immediately next to a road (cross symbols), a rather good agreement is found and the APEX-derived $\mathrm{NO}_{2} \mathrm{VCD}$ are in a similar range as the $\mathrm{VCD}_{\mathrm{IS}}$, and the morning and afternoon results fit well. However, almost all match-ups are located below the 1:1 line suggesting that the a priori $\mathrm{NO}_{2}$ profile is not perfectly suitable to convert the in situ measurements to a columnar quantity. This is particularly true for the sites Opfikon, Stampfenbach, and Schimmelstrasse located directly at a road where the true atmospheric $\mathrm{NO}_{2}$ 
a)

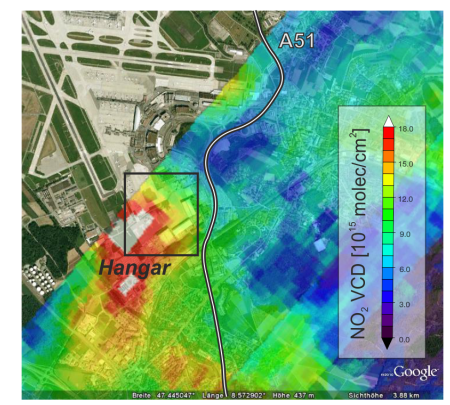

d)

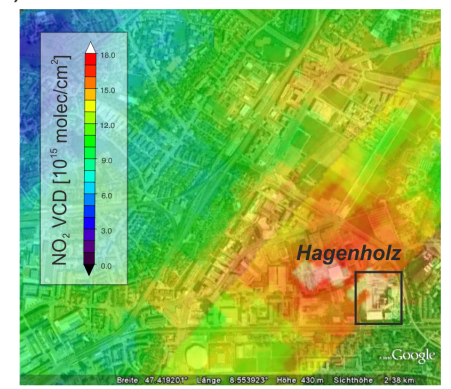

g)

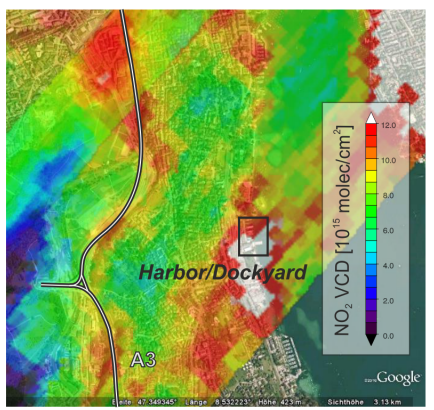

b)

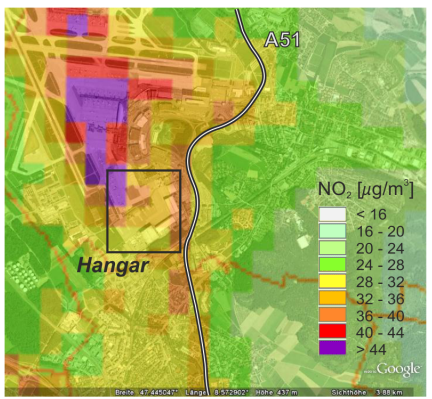

e)

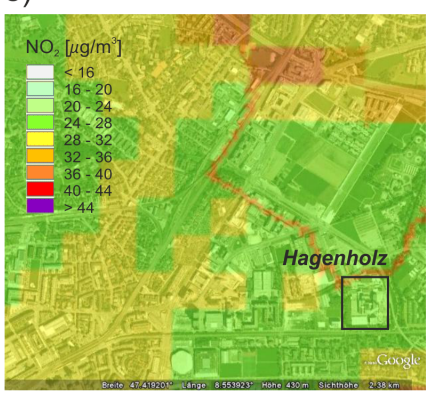

h)

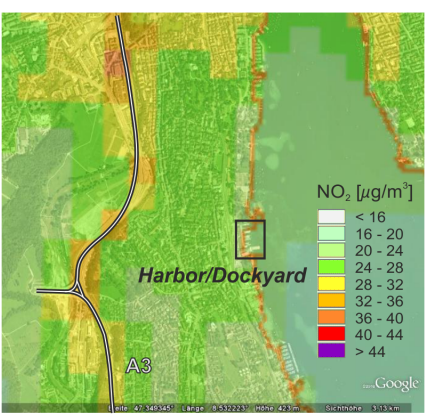

c)

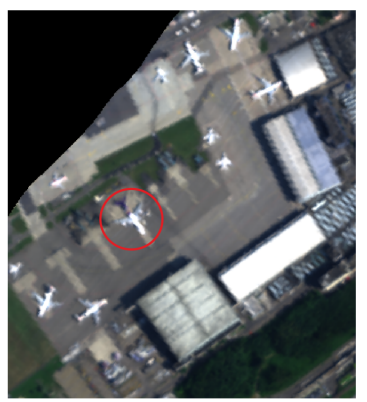

f)

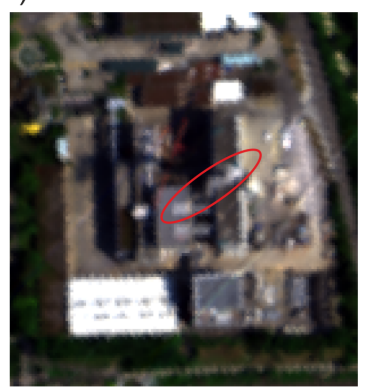

i)

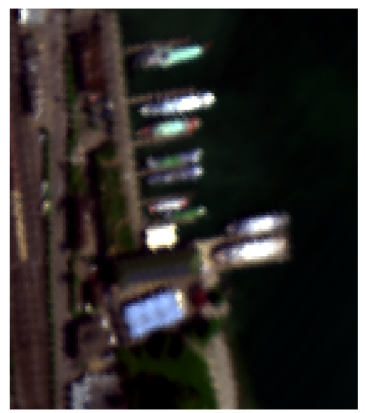

Fig. 13. Exemplary details from $\mathrm{APEX} \mathrm{NO} 2$ VCD derived from the morning overflights over Zurich (left panel) and the corresponding modelled yearly averages of surface $\mathrm{NO}_{2}$ concentrations (middle panel) for comparison (modelled for the year 2010 and available at http://www.gis.zh.ch/gb4/bluevari/gb.asp?app=GB-LHNO210, last access: 12 March 2012). The thin orange lines depict district/community boundaries. Details of the true colour composite from the APEX overflight are illustrated in the right panel, i.e. aircrafts in the hangar area of Zurich airport ((c), aircraft at the engine test site encircled red), plume from the waste incinerator (encircled red, (f)), and vessel on the ramp of the dockyard (i). The outlines of the three subscenes are marked in the left and middle panel as the black rectangles.

profile is probably much more strongly peaked at the surface than the a priori profile leading to a strong overestimation of the $\mathrm{NO}_{2}$ VCD constructed from the in situ data. This further underlines the need for accurate vertical profile information, e.g. by flying vertical $\mathrm{NO}_{2}$ and aerosol profiles with complementary in situ instrumentation. Finally, the chosen approach to construct "in situ VCD" from surface measurements cannot account for the influence of upstream sources present in the APEX-derived column which partly explains the remaining discrepancies.

\section{Conclusions}

We presented the first highly detailed two-dimensional $\mathrm{NO}_{2}$ fields derived from the airborne APEX imaging spectrometer taking advantage of its unique combination of high spectral and spatial resolution and high number of pixels. Radiance data were acquired twice over Zurich, Switzerland, in the morning (10:00 LT) and afternoon (17:30 LT) of a cloud-free summer day in June 2010 . The main results and conclusions from this study can be summarized as follows:

1. Although not primarily designed to retrieve atmospheric constituents, APEX is clearly sensitive toward $\mathrm{NO}_{2}$ above typical European background concentrations. The DOAS analysis revealed a mean dSCD of 


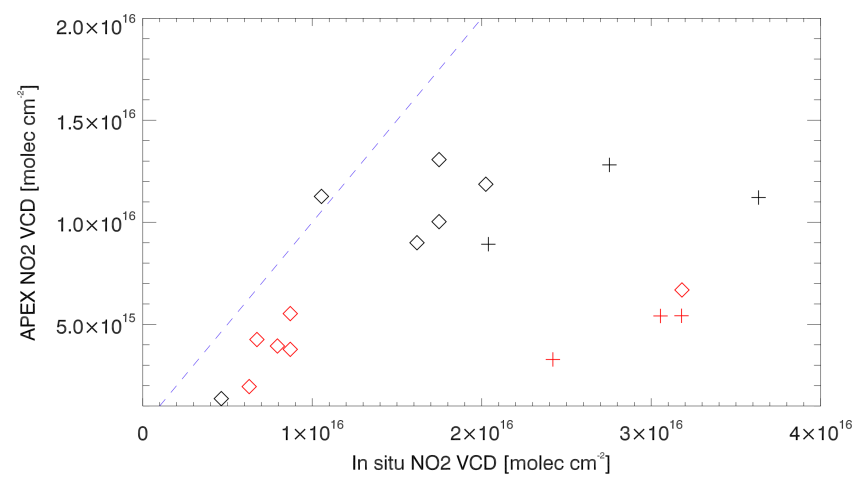

Fig. 14. Scatter plot between surface in-situ $\mathrm{NO}_{2} \mathrm{VCD}$ and APEXderived VCD for the morning (black symbols) and afternoon overflights (red symbols). Crosses denote in situ sites immediately next to a road. The 1:1 line is plotted as the dotted blue line.

$9.2 \times 10^{15}$ molec $\mathrm{cm}^{-2}$ and $3.9 \times 10^{15}$ molec $^{-2}$ for the morning and afternoon overflights with a mean fitting error of around $2.4 \times 10^{15}$ molec $\mathrm{cm}^{-2}$ for both.

2. The results revealed very convincing spatial distributions of $\mathrm{NO}_{2} \mathrm{VCD}$ over the greater Zurich area, e.g. high abundances downwind of the runways of Zurich airport, in the city, over a shopping area, and around a waste incinerator. Lowest $\mathrm{NO}_{2}$ was found in remote places like the forested hills around the greater Zurich area. APEX is thus clearly suitable to detect individual $\mathrm{NO}_{2}$ pollution sources.

3. The $\mathrm{NO}_{2}$ maps from the morning and afternoon overflights showed significant differences. Spatial gradients were much more pronounced in the morning than in the afternoon which can be explained by the much stronger winds and hence stronger dilution in the afternoon. Using APEX observations, it is also possible to roughly capture the diurnal cycle of atmospheric $\mathrm{NO}_{2}$ as the morning overflights exhibited higher $\mathrm{NO}_{2}$ than the afternoon overflights.

4. APEX $\mathrm{NO}_{2} \mathrm{VCD}$ were in reasonably good agreement $(R=0.61)$ with ground-based in-situ measurements from air quality networks considering the limitations and difficulties of comparing a columnar quantity with surface concentration. This further underlines the good performance of APEX and the capacity to capture atmospheric $\mathrm{NO}_{2}$ from its data.

The overall quality of the APEX-retrieved $\mathrm{NO}_{2} \mathrm{VCD}$ also depends on external parameters which should already be accounted for during flight planning. Based on the findings of this study, an adjustment of the APEX data acquisition mode is proposed for $\mathrm{NO}_{2}$ retrieval applications to optimize SNR in the VIS spectral region, e.g. by increasing the data integration time. Enhanced pixel sizes along-track as a consequence of longer integration times were found to be less critical for this application. On the other hand, a longer integration time will potentially lead to signal saturation in the NIR spectral region which may cause problems for the detector readout and the smearing correction. Specific NIR filters might be used to compensate this effect. Further, pollution-free regions should be present in the imaged area in order to select appropriate reference spectra. These spectra should, if possible, be acquired over bright surfaces. The spectral calibration and slit function characterisation with QDOAS pointed to a doubling of the spectral resolution in-flight compared to pre-flight laboratory characterisation. Possible causes for this discrepancy are currently under investigation, and such findings might help to optimize future instrument setups. Finally, future flight campaigns should also aim at measuring $\mathrm{NO}_{2}$ and aerosol profiles which would valuably support the retrieval as well as the interpretation of the results.

The findings of this study clearly reveal a high spatiotemporal variability of $\mathrm{NO}_{2}$. Airborne-based $\mathrm{NO}_{2}$ retrieval, such as presented in this study, allows detecting $\mathrm{NO}_{2}$ emission sources, provides valuable input for $\mathrm{NO}_{2}$ emission modelling, and helps to strengthen the link between air quality models and satellite $\mathrm{NO}_{2}$ products. This all together enables to increase the knowledge on processes and characteristics of $\mathrm{NO}_{2}$ tropospheric distribution. Additional and complementary APEX flights have been carried out in the meantime and others are currently in planning. The growing database of observations will be used to enhance the APEX $\mathrm{NO}_{2}$ retrievals but also to gain knowledge on spatio-temporal $\mathrm{NO}_{2}$ distribution.

Acknowledgements. The authors acknowledge Hyper-Swiss-Net which is jointly funded by the Swiss University Conference and the ETH Board as an Innovation/Cooperation project (Reference number C-19). We like to thank NABEL and OSTLUFT for providing in-situ measurements. The QDOAS team at BIRA is supported by the Belgian Science Policy, in particular through the AGACC-II and PRODEX A3C projects. We thank the APEX team for providing and coordinating the APEX flight activities and Andreas Hüni for fruitful discussions.

Edited by: A. J. M. Piters

\section{References}

Beirle, S., Platt, U., von Glasow, R., Wenig, M., and Wagner, T.: Estimate of nitrogen oxide emissions from shipping by satellite remote sensing, Geophys. Res. Lett., 31, L18102, doi:10.1029/2004GL020312, 2004.

Beirle, S., Boersma, K. F., Platt, U., Lawrence, M. G., and Wagner, T.: Megacity Emissions and Lifetimes of Nitrogen Oxides Probed from Space, Science, 333, 1737-1739, doi:10.1126/science.1207824, 2011.

Bell, J. N. B. and Treshow, M.: Air Pollution and Plant Life, John Wiley \& Sons Ltd., Chichester, UK, 2002. 
Boersma, K. F., Eskes, H. J., and Brinksma, E. J.: Error analysis for tropospheric $\mathrm{NO}_{2}$ retrieval from space, J. Geophys. Res., 109, D04311, doi:10.1029/2003JD003962, 2004.

Boersma, K. F., Eskes, H. J., Veefkind, J. P., Brinksma, E. J., van der A, R. J., Sneep, M., van den Oord, G. H. J., Levelt, P. F., Stammes, P., Gleason, J. F., and Bucsela, E. J.: Near-real time retrieval of tropospheric $\mathrm{NO}_{2}$ from OMI, Atmos. Chem. Phys., 7, 2103-2118, doi:10.5194/acp-7-2103-2007, 2007.

Boersma, K. F., Jacob, D. J., Trainic, M., Rudich, Y., DeSmedt, I., Dirksen, R., and Eskes, H. J.: Validation of urban $\mathrm{NO}_{2}$ concentrations and their diurnal and seasonal variations observed from the SCIAMACHY and OMI sensors using in situ surface measurements in Israeli cities, Atmos. Chem. Phys., 9, 3867-3879, doi:10.5194/acp-9-3867-2009, 2009.

Brunekreef, B. and Holgate, S. T.: Air pollution and health, Lancet, 360, 1233-1242, doi:10.1016/S0140-6736(02)11274-8, 2002.

Bruns, M., Buehler, S. A., Burrows, J. P., Richter, A., Rozanov, A., Wang, P., Heue, K. P., Platt, U., Pundt, I., and Wagner, T.: $\mathrm{NO}_{2}$ Profile retrieval using airborne multi axis UV-visible skylight absorption measurements over central Europe, Atmos. Chem. Phys., 6, 3049-3058, doi:10.5194/acp-6-3049-2006, 2006.

Chance, K. and Kurucz, R. L.: An improved high-resolution solar reference spectrum for Earth's atmosphere measurements in the ultraviolet, visible, and near infrared, J. Quant. Spectrosc. Ra., 111, 1289-1295, 2010.

D’Odorico, P., Alberti, E., and Schaepman, M. E.: In-flight spectral performance monitoring of the Airborne Prism Experiment, Appl. Opt., 49, 3082-3091, 2010.

D’Odorico, P., Guanter, L., Schaepman, M. E., and Schläpfer, D.: Performance assessment of onboard and scene-based methods for Airborne Prism Experiment spectral characterization, Appl. Opt., 50, 4755-4764, 2011.

Fayt, C., De Smedt, I., Letocart, V., Merlaud, A., Pinardi, G., and Van Roozendael, M.: QDOAS Software user manual, available at: http://uv-vis.aeronomie.be/software/QDOAS/index.php (last access: 12 March 2012), 2011.

Heckel, A., Kim, S.-W., Frost, G. J., Richter, A., Trainer, M., and Burrows, J. P.: Influence of low spatial resolution a priori data on tropospheric $\mathrm{NO}_{2}$ satellite retrievals, Atmos. Meas. Tech., 4, 1805-1820, doi:10.5194/amt-4-1805-2011, 2011.

Hermans, C., Vandaele, A. C., Fally, S., Carleer, M., Colin, R., Coquart, B., Jenouvrier, A., and Mérienne, M. F.: Absorption cross section of the collision-induced bands of oxygen from the UV to the NIR, in: NATO Advanced Research Workshop: Weakly Interacting Molecular Pairs: Unconventional Absorbers of Radiation in the Atmosphere, St. Petersburg, Russia, 2002.

Heue, K.-P., Richter, A., Bruns, M., Burrows, J. P., v. Friedeburg, C., Platt, U., Pundt, I., Wang, P., and Wagner, T.: Validation of SCIAMACHY tropospheric $\mathrm{NO}_{2}$-columns with AMAXDOAS measurements, Atmos. Chem. Phys., 5, 1039-1051, doi:10.5194/acp5-1039-2005, 2005.

Heue, K.-P., Wagner, T., Broccardo, S. P., Walter, D., Piketh, S. J., Ross, K. E., Beirle, S., and Platt, U.: Direct observation of two dimensional trace gas distributions with an airborne Imaging DOAS instrument, Atmos. Chem. Phys., 8, 6707-6717, doi:10.5194/acp-8-6707-2008, 2008.

Huijnen, V., Eskes, H. J., Poupkou, A., Elbern, H., Boersma, K. F., Foret, G., Sofiev, M., Valdebenito, A., Flemming, J., Stein, O., Gross, A., Robertson, L., D'Isidoro, M., Kioutsioukis, I., Friese,
E., Amstrup, B., Bergstrom, R., Strunk, A., Vira, J., Zyryanov, D., Maurizi, A., Melas, D., Peuch, V.-H., and Zerefos, C.: Comparison of $\mathrm{OMI} \mathrm{NO}_{2}$ tropospheric columns with an ensemble of global and European regional air quality models, Atmos. Chem. Phys., 10, 3273-3296, doi:10.5194/acp-10-3273-2010, 2010.

Holben, B. N., Eck, T. F., Slutsker, I., Tanre, D., Buis, J. P., Setzer, A., Vermote, E., Reagan, J. A., Kaufman, Y. J., Nakajima, T., Lavenu, F., Jankowiak, I., and Smirnov, A.: AERONET - A federated instrument network and data archive for aerosol characterization, Remote Sens. Environ., 66, 1-16, 1998.

Itten K. I., Dell'Endice F., Hueni A., Kneubühler M., Schläpfer D., Odermatt D., Seidel F., Huber S., Schopfer J., Kellenberger T., Bühler Y., D'Odorico P., Nieke J., Alberti E., and Meuleman K.: APEX - the Hyperspectral ESA Airborne Prism Experiment, Sensors, 8, 6235-6259, doi:10.3390/s8106235, 2008.

Jaeglé, L., Jacob, D. J., Brune, W. H., Tan, D., Faloona, I., Weinheimer, A. J., Ridley, B. A., Campos, T. L., and Sachse, G. W.: Sources of $\mathrm{HO}_{\mathrm{x}}$ and production of ozone in the upper troposphere over the United States, Geophys. Res. Lett., 25, 1705$1708,1998$.

Jehle, M., Hueni, A., Damm, A., D’Odorico, P., Kneubühler, M., Schläpfer, D., and Schaepman, M. E.: APEX - current status, performance and product generation. Proc. IEEE Sensors 2010 Conference, Waikoloa, Hawaii (USA), 1-4 November 2010, 553537, doi:10.1109/ICSENS.2010.5690122, 2010.

Kim, S.-W., Heckel, A., McKeen, S. A., Frost, G. J., Hsie, E. Y., Trainer, M. K., Richter, A., Burrows, J. P., Peckham, S. E., and Grell, G. A.: Satellite-observed US power plant $\mathrm{NO}_{\mathrm{x}}$ emission reductions and their impact on air quality, Geophys. Res. Lett., 33, L22812, doi:10.1029/2006GL027749, 2006.

Palmer, P. I., Jacob, D. J., Chance, K., Martin, R. V., Spurr, R. J. D., Kurosu, T. P., Bey, I., Yantosca, R., Fiore, A., and Li, Q. B.: Air mass factor formulation for spectroscopic measurements from satellites: Application to formaldehyde retrievals from the Global Ozone Monitoring Experiment, J. Geophys. Res., 106, 14539-14550, 2001.

Platt, U. and Stutz, J.: Differential Optical Absorption Spectroscopy, Principles and Applications, Springer, Physics of Earth and Space Environments, ISBN 978-3-540-21193-8, 2008.

Popp, C., Wang, P., Brunner, D., Stammes, P., Zhou, Y., and Grzegorski, M.: MERIS albedo climatology for FRESCO+ $\mathrm{O}_{2}$ A-band cloud retrieval, Atmos. Meas. Tech., 4, 463-483, doi:10.5194/amt-4-463-2011, 2011.

Richter, A., Burrows, J. P., Nüß, H., Granier, C., and Niemeier, U.: Increase in tropospheric nitrogen dioxide over China observed from space, Nature, 437, 129-132, doi:10.1038/nature04092, 2005.

Richter, R. and Schläpfer, D.: Geo-atmospheric processing of airborne imaging spectrometry data. Part 2: atmospheric/topographic correction, Int. J. Remote Sens., 23, 2631-2649, 2002.

SAEFL: Modelling of $\mathrm{NO}_{2}$ and benzene ambient concentrations in Switzerland 2000 to 2020, Environmental Documentation No 188 Air, Berne: Swiss Agency for the Environment, Forests, and Landscape, 64 pp., 2004.

Schläpfer, D. and Richter, R.: Geo-atmospheric processing of airborne imaging spectrometry data. Part 1: parametric orthorectification, Int. J. Remote Sens., 23, 2609-2630, 2002. 
Seidel, F. C., Kokhanovsky, A. A., and Schaepman, M. E.: Fast retrieval of aerosol optical depth and its sensitivity to surface albedo using remote sensing data, Atmos. Res., 116, 22-23, doi:10.1016/j.atmosres.2011.03.006, 2011.

Spurr, R.: LIDORT and VLIDORT: Linearized pseudo-spherical scalar and vector discrete ordinate radiative transfer models for use in remote sensing retrieval problems, in: Light scattering reviews, edited by: Kokhanovsky, A., Berlin, Springer, 229-271, 2008.

Valks, P., Pinardi, G., Richter, A., Lambert, J.-C., Hao, N., Loyola, D., Van Roozendael, M., and Emmadi, S.: Operational total and tropospheric $\mathrm{NO}_{2}$ column retrieval for GOME-2, Atmos. Meas. Tech., 4, 1491-1514, doi:10.5194/amt-4-1491-2011, 2011.

Valin, L. C., Russell, A. R., Bucsela, E. J., Veefkind, J. P., and Cohen, R. C.: Observation of slant column $\mathrm{NO}_{2}$ using the superzoom mode of AURA-OMI, Atmos. Meas. Tech., 4, 1929-1935, doi:10.5194/amt-4-1929-2011, 2011.

van der A, R. J., Eskes, H. J., Boersma, K. F., van Noije, T. P. C., Van Roozendael, M., De Smedt, I., Peters, D. H. M. U, and Meijer, E. W.: Trends, seasonal variability and dominant $\mathrm{NO}_{\mathrm{x}}$ source derived from a ten year record of $\mathrm{NO}_{2}$ measured from space, $\mathrm{J}$. Geophys. Res., 113, D04302, doi:10.1029/2007JD009021, 2008.
Voigt, S., Orphal, J., and Burrows, J. P.: The temperature and pressure dependence of the absorption cross sections of $\mathrm{NO}_{2}$ in the $250-800 \mathrm{~nm}$ region measured by Fourier-transform spectroscopy, J. Photochem. Photobiol. A., 149, 1-7, 2002.

Wang, P., Richter, A., Bruns, M., Rozanov, V. V., Burrows, J. P., Heue, K.-P., Wagner, T., Pundt, I., and Platt, U.: Measurements of tropospheric $\mathrm{NO}_{2}$ with an airborne multi-axis DOAS instrument, Atmos. Chem. Phys., 5, 337-343, doi:10.5194/acp-5-337-2005, 2005.

Zhou, Y., Brunner, D., Boersma, K. F., Dirksen, R., and Wang, P.: An improved tropospheric $\mathrm{NO}_{2}$ retrieval for OMI observations in the vicinity of mountainous terrain, Atmos. Meas. Tech., 2, 401-416, doi:10.5194/amt-2-401-2009, 2009.

Zhou, Y., Brunner, D., Spurr, R. J. D., Boersma, K. F., Sneep, M., Popp, C., and Buchmann, B.: Accounting for surface reflectance anisotropy in satellite retrievals of tropospheric $\mathrm{NO}_{2}$, Atmos. Meas. Tech., 3, 1185-1203, doi:10.5194/amt-3-11852010, 2010.

Zhou, Y., Brunner, D., Hueglin, C., Henne, S., and Staehelin, J.: Changes in OMI tropospheric $\mathrm{NO}_{2}$ columns over Europe from 2004 to 2009 and the influence of meteorological variability, Atmos. Environ, 46, 482-495, 2012. 